\title{
EDUCAÇÃO CORPORATIVA COMO FERRAMENTA PARA ESTIMULAR A INOVAÇÃO NAS ORGANIZAÇÕES: UMA REVISÃO DE LITERATURA
}

DOI: http://dx.doi.org/10.18616/pidi12

Regina Wundrack do Amaral Aires - UFSC E-mail: regina.amaral.aires@gmail.com

Patrícia de Sá Freire - UFSC E-mail: patriciadesafreire@gmail.com João Artur de Souza - UFSC 


\section{INTRODUÇÃO}

Desde a década de 1990, a gestão do conhecimento passou a ser estratégica para qualquer organização que pretende manter-se no mercado e consolidar vantagem competitiva sustentável. "Junto com essa realidade vem a constatação de que a inovação permanente é um fator crítico de sucesso das organizações." (TEIXEIRA FILHO, 2000, p. 42). O condutor central da inovação, segundo a OCDE (2005), é a gestão de conhecimento.

A dinâmica do mundo competitivo atual exige respostas rápidas das organizações, destacando-se aquelas que conseguem, com mais agilidade e maestria, gerir seu conhecimento. Nesse sentido, Teixeira Filho (2000) e Davenport e Prusak (1998) defendem que a verdadeira vantagem competitiva está na capacidade e na velocidade do aprendizado das pessoas nas organizações.

Desse modo, considerando que a dimensão do trabalho mudou do trabalho manual para o intelectual e, por consequência, também o perfil dos trabalhadores, exigindo colaboradores com novas competências e motivados ao aprendizado contínuo (TEIXEIRA FILHO, 2000), a educação corporativa passa a ter um papel de destaque na construção de valores distintivos para a competitividade.

Pela dimensão da inovação, lata e Zimmer (2016) complementam que é preciso o desenvolvimento não somente da organização, mas também de competências dos trabalhadores voltadas para a inovação para que esses tenham condições de inovar nos processos e produtos (bens e serviços), contribuindo para que a empresa desenvolva vantagens competitivas sustentáveis (TEIXEIRA FILHO, 2000).

Corroborando, Senge (2012) afirma que a aprendizagem contínua precisa estar contida na cultura organizacional. É determinante para o sucesso organizacional o investimento contínuo no desenvolvimento de seus trabalhadores. Assim, os frutos desse investimento serão uma força de trabalho capaz de ensinar a aplicar seus novos conhecimentos no dia a dia, de forma a gerar contínuas melhorias e inovações e, por consequência, a desejada vantagem competitiva sustentável.

Nesse contexto, surge a questão de pesquisa: em empresas que visam ao desenvolvimento de vantagens competitivas a partir da inovação em processos e produtos (bens e serviços), qual modelo de educação corporativa deve ser incorporado para potencializar os esforços individuais e organizacionais? 
Com o intuito de buscar respostas para essa questão de pesquisa, este estudo teve como objetivo identificar se a educação corporativa pode ser usada como ferramenta para inovação em processos e produtos, contribuindo para a construção de vantagens competitivas sustentáveis nas organizações.

Pretende-se com este capítulo desenvolver uma reflexão sobre a temática da educação corporativa como ferramenta para inovação, estimulando estudos futuros que aprofundem as contribuições dos diferentes modelos analisados nos diversos setores produtivos. Este estudo se justifica pela relevância que a educação corporativa representa para a promoção da inovação.

\section{INOVAÇÃO}

A inovação é um processo contínuo nas organizações que estão, constantemente, ajustando seus processos e produtos, de modo a buscarem novos conhecimentos, tudo isso com o intuito de elevar a competitividade de seus negócios a um patamar superior, em busca de alguma vantagem competitiva sustentável (OCDE, 2005).

O Manual de Oslo define que "[...] uma inovação é a implementação de um produto (bem ou serviço) novo ou significativamente melhorado, ou um processo, ou um novo modelo de marketing, ou um novo método organizacional nas práticas de negócios, na organização do local de trabalho ou nas relações externas." (OCDE, 2005, p. 55).

Uma empresa, para ser considerada inovadora, deverá ter implementada pelo menos uma inovação, considerando, inclusive, as atividades em processo e abandonadas (OCDE, 2005). As empresas inovadoras possuem processos sistêmicos, personalizados e controlados de inovação, alinhados com suas estratégias e ambições. Um processo de gestão da inovação promove e cria um ambiente para a inovação, para a geração de ideias e projetos inovadores de forma contínua e permanente (IATA; ZIMMER, 2016).

A economia do conhecimento, difundida com a globalização, aumentou a importância da interação entre empresas e outras organizações dos ecossistemas de inovação com o objetivo de adquirir conhecimento especializado. Paralelo a isso, observa-se o crescimento da inovação em serviços nas economias avançadas (OCDE, 2005). 
Na visão da economia do conhecimento, o conhecimento é criado e compartilhado dentro da empresa, entre empresas e com outras organizações. Isso gera a necessidade latente de ter trabalhadores qualificados que possam contribuir de forma sólida na interação com outras empresas e instituições públicas de pesquisa que fazem parte do ecossistema de inovação, conduzindo à exploração do conhecimento (OCDE, 2005). Assim, é evidenciado o trabalho em rede, inter e intraorganizacional.

No Brasil, pode-se observar que, nos últimos anos, houve um investimento exponencial em pesquisa e desenvolvimento. Ocorreram muitos esforços na estruturação de um Sistema Nacional de Inovação (SNI). Em âmbito nacional, um exemplo é o Programa Brasil Maior, que estimulou a criação de novas competências e a promoção da competitividade da indústria por meio de apoio à inovação e ao desenvolvimento tecnológico. Em Santa Catarina, um exemplo é o Programa Catarinense de Inovação ( $\mathrm{PCI})$, que visa sensibilizar as indústrias para o investimento em inovação de forma sistemática e contínua (IATA; ZIMMER, 2016).

Em função das mudanças rápidas do mercado, as empresas precisam inovar com máxima agilidade em seus processos e produtos, por isso a importância do ecossistema de inovação. Não há necessidade de as empresas reinventarem a roda, de procurarem desenvolver soluções caseiras; elas precisam buscar parcerias e atuação em rede, senão o SNI ficará limitado a algumas ilhas de conhecimento (IATA; ZIMMER, 2016).

O SNI é composto por diferentes atores, cada um com uma função distinta. Esse sistema só existe quando há atuação em rede. lata e Zimmer (2016, p. 12) discorrem que "[...] para a efetivação de um ecossistema de inovação é preciso, acima de tudo, que exista conexão e interação entre as partes, do contrário, são apenas instituições isoladas."

Com o passar dos anos, os modelos de inovação evoluíram, na busca de desenvolver as melhores respostas para as organizações, alinhadas ao momento econômico e ao mercado em que estas estavam inseridas. Esse tema será apresentado na próxima seção. 


\section{MODELOS DE INOVAÇÃO}

Para Rothwell (1994 apud GANZER et al., 2014), o processo de inovação tecnológica pode ser dividido em cinco gerações. A cada evolução, a geração anterior é superada. De acordo com o Manual de Oslo (OCDE, 2005), Rothwell (1994 apud GANZER et al., 2014) e lata e Zimmer (2016), uma evolução tecnológica precisa apresentar valor de mercado; para tanto, precisa haver interação dos centros de pesquisa e universidades com as empresas para que a transferência tecnológica aconteça e possa ser validada no setor produtivo a inovação proposta.

No Quadro 1, apresentamos uma breve caracterização dessas cinco gerações que compuseram os modelos linear e interativo de inovação.

\section{Quadro 1 - Modelos de inovação}

\begin{tabular}{|c|c|}
\hline \multicolumn{2}{|c|}{ Modelos de inovação } \\
\hline Modelo linear & 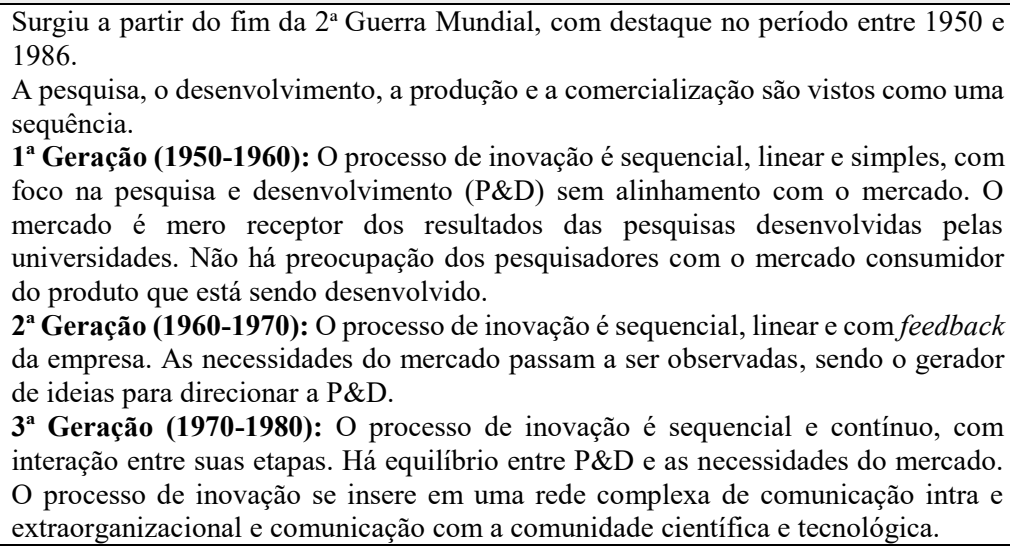 \\
\hline $\begin{array}{l}\text { Modelo } \\
\text { interativo }\end{array}$ & 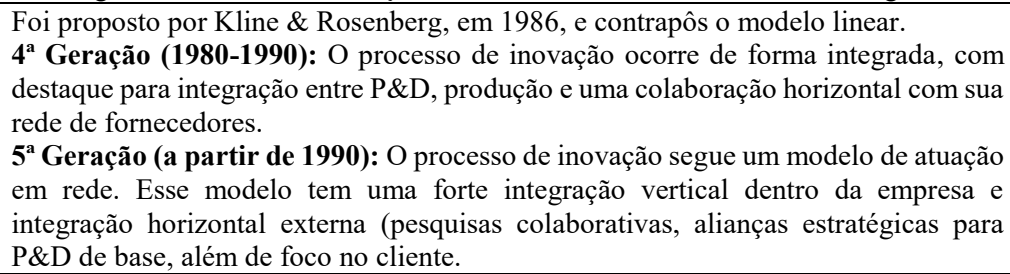 \\
\hline
\end{tabular}

Fonte: Elaborado pelos autores (2016), baseado em Conde e Araújo-Jorge (2003) e Gazer et al. (2014). 
Para Gazer et al. (2014), um modelo de processo de inovação que tem adesão de vários autores, considerado não linear e interativo, é o modelo Hélice Tríplice.

A Hélice Tríplice foi desenvolvida por Henry Etzkowitz e Loet Leydesdorff, em meados dos anos 1990, baseada na relação entre universidadegoverno-empresa, fruto da observação da atuação do Massachussetts Institute of Technology (MIT) MIT - com o polo industrial em seu entorno (ETZKOWITZ, 1994, 2010 apud GOMES; PEREIRA, 2015). Esse modelo contrapõe a tradição shumpeteriana, que relacionada a inovação às empresas, colocando o governo e as universidades em posição de destaque (CONDE; ARAÚJO-JORGE, 2003). De acordo com Valente (2010), a Hélice Tríplice é a metáfora que melhor descreve o mais sustentável modelo de inovação contemporâneo.

O modelo é representado por um espiral de três hélices, as quais representam os três atores do modelo: a universidade, o governo e a empresa. Essas hélices se entrelaçam demonstrando as inter-relações e os fluxos de comunicação propostos pelo modelo (CONDE; ARAÚJO-JORGE, 2003).

De acordo com Fischmann e Cunha (2003 apud GOMES; PEREIRA, 2015), tal configuração de relacionamento entre universidade e empresa justifica-se pelo contexto econômico da sociedade da informação, cujas universidades buscam uma ressignificação de seu papel e suas contribuições para a sociedade e as empresas, além de maior competitividade no mercado globalizado. O papel do governo se insere como agente estimulador de políticas que impulsionam a inovação a fim de colocar a economia de seu país em patamares competitivos no mercado globalizado.

O modelo Hélice Tríplice pode ser considerado o modelo de inovação mais contemporâneo, pois é adaptável a diversas realidades e é o que está sendo seguido por vários países desenvolvidos. De acordo com Valente (2010), o Brasil foi apontado por Henry Etzkovitz, em 2010, como o terceiro país com o melhor modelo de hélice tríplice, precedido pela Suécia e pelos Estados Unidos. Tal reconhecimento é atribuído aos inúmeros investimentos em incubadoras e associações, os quais estimulam a cultura da inovação no país (VALENTE, 2010).

Essa interação entre os diversos atores - universidade, governo e empresa -, gera inúmeros conhecimentos que precisam ser gerenciados para que, depois de processados, possam gerar novos conhecimentos e contribuir para a construção de vantagens competitivas sustentáveis das organizações. Na próxi- 
ma seção, apresentaremos os referenciais teóricos para a criação e a gestão do conhecimento para a inovação.

\section{CRIAÇÃO E GESTÃO DO CONHECIMENTO PARA A INOVAÇÃO}

A criação do conhecimento organizacional é a chave para a inovação nos negócios. É a base das empresas japonesas, que são peritas em fomentar a inovação de forma contínua, incremental e em espiral. Esses são os ingredientes para a obtenção de vantagens competitivas sustentáveis (NONAKA; TAKEUCHI, 1997).

A indústria japonesa, ao longo de sua história, provou que sua fórmula de inovar, com o olhar sempre para o ambiente externo e interno, para criar conhecimento e inovar em seus produtos (bens e serviços), dá certo. São exemplos a Canon, que apostou no futuro, desenvolvendo a primeira máquina fotográfica computadorizada; e a Honda, que desenvolveu um motor de alto rendimento antes da crise do petróleo (NONAKA; TAKEUCHI, 1997).

A gestão do conhecimento, implícito e explícito, é o combustível para a inovação nas organizações, seja em seus processos de gestão ou em seus produtos (bens e serviços). A essência da inovação é recriar com base em ideais e ideias. Para isso, é necessário um compromisso pessoal dos funcionários com a missão da organização (NONAKA; TAKEUCHI, 1997).

No atual contexto do mundo corporativo, o conhecimento destaca-se como fator de competividade de mercado. As dinâmicas do capitalismo desafiam as organizações a se reinventarem para garantir sua perenidade e competitividade. Desse modo, investir em gestão do conhecimento passa a ser estratégico (SILVA, 2004). Essa constatação pode ser confirmada em diversas bibliografias que tratam do tema Gestão do Conhecimento (GC), conforme apresentado no quadro a seguir: 
Quadro 2 - Importância da Gestão do Conhecimento (GC)

\begin{tabular}{|c|c|}
\hline Autores & Citações sobre a importância da GC \\
\hline $\begin{array}{l}\text { Davenport e Prusak } \\
(1998)\end{array}$ & $\begin{array}{l}\text { O conhecimento é fundamental para o sucesso e a sobrevivência das } \\
\text { organizações. }\end{array}$ \\
\hline $\begin{array}{l}\text { Teixeira Filho }(2000, \mathrm{p} . \\
17-21)\end{array}$ & $\begin{array}{l}\text { "O conhecimento tornou-se o fator econômico mais importante no ambiente } \\
\text { competitivo das organizações. Conhecimento não no sentido abstrato, ou } \\
\text { teórico, mas aplicado no dia a dia das empresas. Conhecimento sobre seu } \\
\text { mercado, seus clientes, sua tecnologia, seus concorrentes, etc. [...] chegamos } \\
\text { a um estágio em que o conhecimento é um fator decisivo para a } \\
\text { sobrevivência da empresa no novo ambiente competitivo". }\end{array}$ \\
\hline Klein (1998, p. 2) & $\begin{array}{l}\text { "Empresas que adotam uma abordagem estratégica à gestão de seu capital } \\
\text { intelectual veem uma oportunidade de melhorar suas posições de mercado } \\
\text { relativas a organizações que continuam a gerenciar tal capital de forma } \\
\text { oportunista". }\end{array}$ \\
\hline Cianconi (2001, p. 15) & $\begin{array}{l}\text { "A competitividade crescente e a aceleração do desenvolvimento } \\
\text { tecnológico de nossos dias fazem com que o detentor de informações certas, } \\
\text { acessadas na hora certa, mantenha vantagem competitiva". }\end{array}$ \\
\hline $\begin{array}{l}\text { Quinn et al. (1997 apud } \\
\text { da Silva, 2004, p. 143) }\end{array}$ & $\begin{array}{l}\text { "A implantação coordenada da gestão do conhecimento cria uma vantagem } \\
\text { competitiva sustentável e de difícil imitação, pois está enraizada nas pessoas } \\
\text { que trabalham na empresa, e não em recursos físicos, que são facilmente } \\
\text { imitáveis pelos concorrentes". }\end{array}$ \\
\hline $\begin{array}{l}\text { Toumi (2001 apud } \\
\text { Rossetti; Morales, 2007, } \\
\text { p. 126) }\end{array}$ & $\begin{array}{l}\text { "O sucesso do negócio está ficando cada vez mais dependente da inovação } \\
\text { e do conhecimento, que estão mudando as formas tradicionais de organizar } \\
\text { os negócios nas empresas". }\end{array}$ \\
\hline
\end{tabular}

Fonte: Elaborado pelos autores (2016).

Para Teixeira Filho (2000, p. 22), “A gestão do conhecimento pode ser vista como uma coleção de processos que governa a criação, disseminação e utilização do conhecimento para atingir plenamente os objetivos da organização."

Nos modernos conceitos de GC, acredita-se que as empresas de classe mundial devem seguir o fundamento de aprendizado organizacional, aprender com suas práticas e melhorá-las a cada ciclo, ou seja, cultivar a "[...] busca, o alcance de um novo patamar de conhecimento para a organização por meio da percepção, reflexão, avaliação e compartilhamento de experiências." (FNQ, 2016, p. 10).

Para Nonaka e Takeuchi (1997), há quatro formas de transformar o conhecimento tácito em explícito: pela socialização, pela externalização, pela combinação e pela internalização. Para que esse espiral do conhecimento aconteça, gere valor e vantagens competitivas sustentáveis, é necessária a integração entre os processos empresariais e as estratégias competitivas. Para isso, faz-se necessária a integração das pessoas, das redes de informação e o emprego da tecnologia da informação. Davenport e Prusak (1998, p. 14-15) destacaram que 
Novo é reconhecer o conhecimento como um ativo corporativo e entender a necessidade de geri-lo e cercá-lo do mesmo cuidado dedicado à obtenção de valor de outros ativos mais tangíveis. A necessidade de extrair o máximo de valor do conhecimento organizacional é maior agora que no passado.

Teixeira Filho (2000), Davenport e Prusak (1998) afirmaram que em uma economia globalizada, altamente competitiva, com ciclos de criação de produtos cada vez mais curtos, as organizações acabam se diferenciando pelo que elas sabem e pela forma como conseguem usar esse conhecimento, ou seja, o conhecimento passa a ser a maior vantagem competitiva sustentável.

Davenport e Prusak (1998) afirmaram, ainda, que a gestão do conhecimento deve ser usada para potencializar a economia, as melhorias e os aumentos da produtividade. Na mesma linha, Teixeira Filho (2000, p. 22) apresentou que "Um melhor conhecimento pode levar a melhores decisões em marketing, vendas, produção, distribuição, e assim por diante". Daí o interesse das organizações em investir em gestão do conhecimento e sua preocupação com seu capital intelectual para ter vantagem competitiva.

As organizações que se mantiveram no mercado nas últimas décadas foram aquelas que se reinventaram. Assim, segundo Davenport e Prusak (1998, p. 16).

Cada vez mais as atividades baseadas no conhecimento e voltadas para o desenvolvimento de produtos e processos estão tornando as principais funções internas das empresas e aquelas com maior potencial de obtenção de vantagem competitiva.

Nessa conjuntura de mercado global, com mais tecnologias à disposição e processos mais modernos de produção, os concorrentes reproduzem rapidamente a maioria dos produtos e serviços. Não há maneira de manter o segredo de produção por muito tempo. As vantagens de novos produtos são sustentáveis por um curto espaço de tempo. Para Davenport e Prusak (1998, p. 20),

[...] porém, a empresa rica em conhecimento e gestora do conhecimento terá passado para um novo nível de qualidade, criatividade ou eficiência. A vantagem do conhecimento é sustentável porque gera retornos crescentes e dianteiras continuadas. 
"A empresa começa a perceber a importância de transformar seu conhecimento realmente em um ativo a serviço da organização, e não apenas em propriedade de indivíduos ou grupos internos." (TEIXEIRA FILHO, 2000, p. 41).

Pode-se perceber que a GC está sustentada por três pilares: pessoas, tecnologias e processos de negócios (DAVENPORT; PRUSAK, 1998). Nota-se que a gestão do conhecimento é um desafio da gestão de pessoas nas organizações, fato que demonstra a relevância deste estudo e justifica a necessidade da educação corporativa para potencializar as capacidades dos trabalhadores e superar eventuais lacunas da educação acadêmica.

\section{EDUCAÇÃO CORPORATIVA}

O conceito de Educação Corporativa (EC) data da metade do século XX e consolida-se nas décadas de 1980, 1990 e início do século XXI, com um foco intenso no Treinamento e Desenvolvimento (T\&D) dos trabalhadores (MEISTER, 1999).

A finalidade básica da EC em uma organização é fomentar "[...] o desenvolvimento e a instalação das competências empresariais e humanas consideradas críticas para a viabilização das estratégias de negócios." (EBOLI, 2004, p. 48), de forma sistemática, estratégica e contínua.

A evolução da Educação Corporativa está intimamente ligada com os sistemas de produção e a própria evolução da educação, conforme apresentado no Quadro 3. 
Quadro 3 - Evolução da Educação

\begin{tabular}{|c|c|}
\hline Período & Características \\
\hline $\begin{array}{l}\text { Primeira Revolução } \\
\text { Industrial - segunda metade } \\
\text { do século XVII }\end{array}$ & $\begin{array}{l}\text { Substituição da produção artesanal pela produção fabril. } \\
\text { Migração urbana e instauração da miséria. } \\
\text { Preocupação com a universalização do ensino. } \\
\text { Sistema de produção taylorista-fordista - divisão do trabalho manual e } \\
\text { intelectual. } \\
\text { Divisão social da educação, a elite recebia educação superior para } \\
\text { gerenciar as empresas e a massa recebia educação técnica para realizar } \\
\text { operações repetitivas. }\end{array}$ \\
\hline $\begin{array}{l}\text { Segunda Revolução } \\
\text { Industrial - início do século } \\
\mathrm{XX}\end{array}$ & $\begin{array}{l}\text { Automação e produção em massa. } \\
\text { Estabelecimento da economia do bem-estar social, aumento de } \\
\text { empregos, salários e benefícios. } \\
\text { Educação fundamentada no raciocínio, valores éticos e acumulação do } \\
\text { conhecimento de forma organizada. } \\
\text { Sistema de produção taylorista-fordista - divisão do trabalho manual e } \\
\text { intelectual. }\end{array}$ \\
\hline $\begin{array}{l}\text { Terceira Revolução } \\
\text { Industrial - origem nos anos } \\
1970 \text { (segunda metade do } \\
\text { século XX) }\end{array}$ & $\begin{array}{l}\text { Surgimento da informática e avanço das comunicações. } \\
\text { Estabelece um caráter social excludente e a educação passa a ser um pré- } \\
\text { requisito para o cidadão sob três dimensões: produção, consumo e vida } \\
\text { social. } \\
\text { Surge a sociedade do conhecimento. } \\
\text { Sistema de produção flexível. } \\
\text { Desenvolvimento de pessoas (trabalhadores) com autonomia, iniciativa } \\
\text { e dinamismo. Valorização do autodesenvolvimento e aprendizado } \\
\text { contínuo. }\end{array}$ \\
\hline
\end{tabular}

Fonte: Elaborado pelos autores (2016), baseado em Souza (2005), Aranha (1996 apud REIS; SILVA; EBOLI, 2010) e Eboli (2004).

De acordo com os debates do Fórum Econômico Mundial, realizado em janeiro de 2016, em Davos, na Suíça, estamos vivendo o início da quarta Revolução Industrial. Essa nova fase será marcada por profundas mudanças no mercado de trabalho e nos modelos de negócios (EBC, 2016). A internet das coisas e a big data transformarão a economia; a realidade virtual possibilitar-nos-á novas formas de consumo e interação com as informações. Robôs, softwares, comando por voz e ferramentas de impressão 3D farão parte do nosso dia a dia (FORBES, 2016). O mercado de trabalho será dramaticamente afetado, inclusive trabalhos intelectuais mais simples serão substituídos pela robotização. A ameaça aos empregos não estará apenas nas indústrias, o setor de serviços será altamente impactado por softwares inteligentes (TAURION, 2016).

A evolução da EC acompanhou as revoluções industriais, buscando dar respostas ao que o mercado precisava em cada fase. No Quadro 4, podemos observar as características de cada modelo de aprendizagem da educação corporativa. 
Quadro 4 -Evolução da Educação Corporativa

\begin{tabular}{|l|l|}
\hline \multicolumn{1}{|c|}{$\begin{array}{c}\text { Estágios dos modelos de } \\
\text { aprendizagem corporativa }\end{array}$} & \multicolumn{1}{c|}{ Características } \\
\hline Formação e Treinamento & $\begin{array}{l}\text { Iniciou em 1920 até o início da década de 1970. } \\
\text { Instrução de funcionários para a melhoria de habilidades operacionais. }\end{array}$ \\
\hline Educação Corporativa & $\begin{array}{l}\text { Surgiu no final da década de 1950 com os primeiros centros de educação } \\
\text { corporativa da General Motors e da McDonald's. } \\
\text { Foco na formação de funcionários para tarefas operacionais alinhadas } \\
\text { com a estratégia da organização. }\end{array}$ \\
\hline Aprendizagem em Rede & $\begin{array}{l}\text { Surgiu na década de 70 com a necessidade de ir além do treinamento e } \\
\text { desenvolvimento (T\&D). } \\
\text { Foco no desenvolvimento de capacidades, habilidades e atitudes } \\
\text { operacionais, táticas e estratégicas. Surgem os programas de qualidade } \\
\text { total, o desenvolvimento de lideranças e a profissionalização da cadeira } \\
\text { de suprimentos. } \\
\text { Surge o termo Universidade Corporativa, com o intuito de denominar a } \\
\text { gama de ações de educação corporativa realizada pelas organizações. }\end{array}$ \\
\hline
\end{tabular}

Fonte: Elaborado pelos autores (2016), baseado em Margherita e Secundo (2009) e em Meister (1998).

A Universidade Corporativa (UC), termo cunhado por Meister (1998), abarca o desenvolvimento e a educação dos funcionários, clientes e fornecedores, alinhados com as estratégias da organização, sendo um laboratório de aprendizagem. Outros autores apresentam suas definições para UC, porém todos respeitam a definição inicial de Meister de que a UC vai muito além do treinamento de funcionários para desempenhar tarefas (FREIRE et al., 2016).

A partir da década de 1980 e principalmente na década de 1990, com o cenário de hipercompetitividade mundial, houve a proliferação das Universidade Corporativas (UC), alinhada à necessidade de capacitação e atualização contínua dos trabalhadores (FREIRE et al., 2016).

Nesse período, as organizações perceberam que as Universidades Acadêmicas (UA) não davam as respostas que a formação de seus trabalhadores e importantes stakeholders precisavam para desempenhar suas funções, pois se notou um descompasso na formação acadêmica com as competências requeridas pelo mercado de trabalho. Assim, as organizações assumiram a responsabilidade de capacitação de seus trabalhadores e stakeholders nas UCs, algumas em parceria com UA e fornecedores de conteúdo (MORRISON; MEISTER, 2000; ALLEN, 2002; McGEE, 2006 apud FREIRE et al., 2016). 
Nessa discussão de que a UA não estaria respondendo às necessidades de capacitação dos profissionais para o mundo do trabalho, de acordo com Freire et al. (2016), surgiram várias iniciativas da Academia, no início dos anos 1990, para buscar respostas para a capacitação e a atualização dos trabalhadores, demostrando maior alinhamento da UA às necessidades do mercado de trabalho. Nesse debate, várias terminologias foram atribuídas às UA para demonstrar esse esforço de alinhamento, tais como: Universidade de Serviço (BUCHBINDER; JANICE, 1992; BUCHBINDER, 1993 ), Universidade Responsiva (TIERNEY, 1998), Universidade Inovativa e Universidade Empreendedora (CLARK, 1998), Universidade Empresarial (MARGINSON; CONSIDINE, 2001) e Stakeholder University (JONGBLOED; GOEDEGEBUURE, 2001).

A Stakeholder University está alinhada com o estágio três da aprendizagem corporativa, a aprendizagem em rede, assim definida por Margherita e Secundo (2009). Esse estágio proposto pelos autores fortaleceu-se em meados da década de 90 , com as demandas de desenvolvimento acelerado das tecnologias da informação e comunicação (MARGHERITA; SECUNDO, 2009), período da Terceira Revolução Industrial. Para Meister (1999), o modelo de aprendizagem em rede reforça que o diferencial competitivo está em não somente capacitar seus funcionários, mas também seus fornecedores e clientes. Segundo Freire et al. (2016, p. 3), no século XXI, “[...] a atuação em redes de aprendizagem torna-se o principal caminho para a inovação". A UC deve incluir em seus programas todas as partes interessadas da organização, funcionários, fornecedores, clientes e demais partícipes de sua rede colaborativa. Isso é possível tanto nas organizações privadas quanto nas públicas (FREIRE et al., 2016).

Meister (1999) apresenta dez metas (Quadro 5) que constituem a base de objetivos e princípios da UC que qualquer organização deveria seguir para mobilizar sua força de trabalho na construção de vantagens competitivas sustentáveis no mercado global.

As empresas que aplicam esses princípios em suas UC estão olhando além dos programas de educação de funcionários, ou seja, estão criando sistemas de aprendizagem contínua vinculados às suas estratégias e metas, envolvendo funcionários, clientes e a cadeia de fornecimento (MEISTER, 1999).

Para Abel e Li (2012), baseados em uma pesquisa realizada com uma amostra de 210 participantes, entre clientes de uma empresa de consultoria em educação corporativa e membros da Sociedade Americana de Treinamento e Desenvolvimento, há cinco fatores prioritários para a UC: alinhamento à execu- 
ção, desenvolvimento de habilidades para suportar as necessidades de negócio, avaliação de desempenho e de aprendizagem, parceria com as universidades e tecnologia para apoio a aprendizagem.

Quadro 5 - Objetivos e princípios da UC

\begin{tabular}{|l|}
\hline \multicolumn{1}{|c|}{ Características base de uma Universidade Corporativa (UC) } \\
\hline \begin{tabular}{l} 
1. $\begin{array}{l}\text { Oferecer oportunidades de aprendizagem que deem sustentação às questões empresariais mais importantes } \\
\text { da organização. }\end{array}$ \\
\hline 2. Considerar o modelo de UC um processo e não um espaço físico destinado à aprendizagem. \\
\hline 3. $\begin{array}{l}\text { Elaborar um currículo que incorpore os três Cs: Cidadania Corporativa, Estrutura Contextual e } \\
\text { Competências Básicas. }\end{array}$ \\
\hline 4. Treinar a cadeia de valor e parceiros, inclusive clientes, distribuidores, fornecedores de produtos \\
terceirizados, assim como universidades que possam fornecer os trabalhadores de amanhã.
\end{tabular} \\
\hline 5. Passar do treinamento conduzido pelo instrutor para vários formatos de apresentaçán. \\
\hline 6. Encorajar e facilitar o envolvimento dos líderes com o aprendizado. \\
\hline 7. Passar do modelo de financiamento corporativo por alocação para "autofinaciamento" pelas unidades de \\
negócio. \\
\hline 8. Assumir um foco global no desenvolvimento de soluções de aprendizagem. \\
\hline 9. Criar um sistema de avaliação dos resultados e investimentos. \\
\hline 10. Utilizar a UC para obter vantagem competitiva e entrar em novos mercados. \\
\hline
\end{tabular}

Fonte: Elaborado pelos autores (2016), baseado em Meister (1999).

Além das propostas de modelos de UC apresentadas por Meister (1999) e Abel e Li (2012), há outros autores que propõem estruturas de UC, tais como os modelos de Allen (2002) - baseados em atividades -, os de Antonelli, Cappiello e Pedrini (2013) - baseados em conteúdo - e os de Rademakers (2005) - baseados em programa. Todos os modelos apresentados por esses autores têm as fronteiras da UC limitadas nos muros das organizações, não havendo interação com as partes interessadas, ou seja, com os clientes e fornecedores.

Em 2009, Alessandro Margherita e Giustina Secundo, da Universidade de Salento, na Itália, apresentaram um modelo de UC chamado Stakeholder University, em português Universidade das Partes Interessadas, cuja proposta é um novo modelo de UC, que, além de capacitar os funcionários da organização, estende capacitações a todas as suas partes interessadas, todos os atores que influenciam e são influenciados pelas decisões da organização (MARGHERITA; SECUNDO, 2009). A Stakeholder University é caracterizada por três aspectos determinantes apresentados no Quadro 6.

Para Margherita e Secundo (2009), a Stakeholder University é o modelo de educação corporativa mais elevado. Como podemos perceber no Quadro 6, para que uma UC seja considerada aderente ao modelo Stakeholder University, um fator determinante é a aprendizagem em rede, é o que mais diferencia 
esse modelo dos demais apresentados neste estudo, o que para Freire et al. (2016) denuncia a demanda por um modelo de Universidade Corporativa em Rede (UCR).

\begin{tabular}{|l|l|}
\multicolumn{1}{|c}{ Quadro 6 - Características da Stakeholder University } \\
\multicolumn{1}{|c|}{$\begin{array}{c}\text { Aspectos } \\
\text { determinantes }\end{array}$} & \multicolumn{1}{c|}{ Características } \\
\hline $\begin{array}{l}\text { Alinhamento } \\
\text { estratégico }\end{array}$ & $\begin{array}{l}\text { Objetivos estratégicos de desenvolvimento do capital humano, por meio } \\
\text { de uma forte integração de pesquisa, desenvolvimento de competências e } \\
\text { gestão do conhecimento. Como consequência, a aprendizagem coletiva e o } \\
\text { desenvolvimento da estratégia estão constantemente alinhados à } \\
\text { estratégia de negócios. }\end{array}$ \\
\hline Rede estendida & $\begin{array}{l}\text { Envolvimento estendido de uma ampla gama de stakeholders, } \\
\text { reconhecendo a centralidade do desenvolvimento do capital social e dos } \\
\text { relacionamentos interorganizacionais, além do capital humano. }\end{array}$ \\
\hline Aprendizagem em rede & $\begin{array}{l}\text { Processo de aprendizagem em rede, de criação de conhecimento e } \\
\text { inovação baseado em relacionamentos e interações entre as partes } \\
\text { interessadas, por meio de uma nova geração de tecnologias colaborativas } \\
\text { de trabalho e aprendizagem. }\end{array}$ \\
\hline
\end{tabular}

Fonte: Elaborado pelos autores (2016), baseado em Margherita e Secundo (2009).

O modelo UCR proposto por Freire et al. (2016) se diferencia do Stakeholder University, pois agrega mais dois enfoques advindos da Gestão do Conhecimento: a percepção da (1) UCR como uma unidade formadora de memória de rede, e da (2) Engenharia do Conhecimento como estratégia para a instrumentalização da UCR.

Quando analisada sob o ponto de vista de seu conteúdo, uma UCR é um grande repositório de informação e de conhecimento produzido pela sua rede, a equipe da organização e suas partes interessadas, o qual poderá ser recuperado e reutilizado pelos atores desse ecossistema, a UCR (ANDERSON; SUN, 2010). Ou seja, a memória da UCR estaria disponível para todos da sua rede.

Quanto à Engenharia do Conhecimento como estratégia para a instrumentalização da UCR, essa sistematização tem fundamentação em modelos de conhecimento - que permitem a padronização do armazenamento das informações - e conhecimentos da memória organizacional - que permitam o reuso, a padronização, a representação semântica e as inferências em domínios específicos (FREIRE et al., 2016). 
Freire et al. (2016) propõem que uma UCR tenha as seguintes diretrizes:

\section{Quadro 7 - Diretrizes da UCR}

\begin{tabular}{|c|c|}
\hline Diretrizes & Características \\
\hline Alcance & $\begin{array}{l}\text { 1. Como um ambiente de aprendizagem coletiva orientado às demandas da } \\
\text { organização e dos stakeholders que compõem seu ecossistema de atuação. }\end{array}$ \\
\hline Interconexão & $\begin{array}{l}\text { 2. Com princípios da gestão do conhecimento e foco no desenvolvimento do capital } \\
\text { humano e social por meio da formatação, do treinamento, da educação corporativa e } \\
\text { da aprendizagem em rede. }\end{array}$ \\
\hline $\begin{array}{l}\text { Reconhecimento } \\
\text { dos Stakeholders }\end{array}$ & $\begin{array}{l}\text { 3. Para todos os diferentes interessados no sucesso da estratégia organizacional, } \\
\text { sejam internos ou externos, operacional, gerenciais ou estratégicos. }\end{array}$ \\
\hline Tecnologia & $\begin{array}{l}\text { 4. Com alto nível de confiança, cooperação e conectividade entre a organização, a } \\
\text { sociedade, a universidade tradicional, a universidade corporativa e os institutos de } \\
\text { ciência e tecnologia, criando valor e capital social. }\end{array}$ \\
\hline Foco & $\begin{array}{l}\text { 5. Conteúdo alinhado à estratégia organizacional, podendo ser de nível } \\
\text { operacional, administrativo ou generalista. }\end{array}$ \\
\hline Nível & $\begin{array}{l}\text { 6. Com a perspectiva de obtenção de alguns créditos universitários e diploma na } \\
\text { universidade tradicional. }\end{array}$ \\
\hline \multirow{8}{*}{$\begin{array}{l}\text { Gestão do } \\
\text { Conhecimento }\end{array}$} & $\begin{array}{l}\text { 7. Com a visão de promover a cocriação e coprodução de valor para todos os } \\
\text { stakeholders. }\end{array}$ \\
\hline & $\begin{array}{l}\text { 8. Reter conhecimento por meio do estabelecimento de bases de conhecimento e } \\
\text { de canais de interação e o compartilhamento do conhecimento. }\end{array}$ \\
\hline & $\begin{array}{l}\text { 9. Eliminar as barreiras geográficas no acesso às informações e às expertises, } \\
\text { dentro e fora da organização. }\end{array}$ \\
\hline & $\begin{array}{l}\text { 10. Aumentar a produtividade dos colaboradores e stakeholders pela facilidade em } \\
\text { encontrar conteúdos e expertises. }\end{array}$ \\
\hline & $\begin{array}{l}\text { 11. Promover maior agilidade na comunicação entre as áreas e as unidades e entre } \\
\text { os diferentes stakeholders que compõem o ecossistema organizacional. }\end{array}$ \\
\hline & 12. Implantar meios eficientes para organizar e distribuir as informações na rede. \\
\hline & $\begin{array}{l}\text { 13. Formar base informatizada com as expertises e conhecimentos produzidos pelos } \\
\text { stakeholders nos processos que permeiam as atividades organizacionais. }\end{array}$ \\
\hline & $\begin{array}{l}\text { 14. Alinhar a aplicação das Tecnologias da Informação e Comunicação de acordo } \\
\text { com as necessidades dos processos de gestão do conhecimento em todos os níveis de } \\
\text { interação entre stakeholders que formam a UCR. }\end{array}$ \\
\hline
\end{tabular}

Fonte: Elaborado pelos autores (2016), baseado em Freire et al. (2016).

De acordo com Freire et al.,

A Universidade Corporativa em Rede (UCR) se apresenta como um processo transversal à organização, tendo o objetivo de promover a aprendizagem coletiva de conhecimentos essenciais para o sucesso da estratégia organizacional, em todos os seus níveis estruturais - operacional, tático e estratégico -, bem como de todos os interessados em seus resultados, ou seja, seus stakeholders. (FREIRE et al., 2016, p. 17. Grifo no original).

Assim, identificou-se que o Modelo UCR proposto por Freire et al. (2016) é uma evolução do Modelo Stakeholder University proposto por Mar- 
gherita e Secundo (2009), o qual é o mais contemporâneo constatado nesta pesquisa.

\section{METODOLOGIA}

Este estudo classifica-se como uma pesquisa teórica, com objetivos exploratório-descritivos realizados por meio de uma revisão bibliográfica (FREIRE, 2013), a partir de artigos científicos e de livros de autores referência quanto ao tema, em especial a brasileira Marisa Eboli e a norte-americana Jeanne C. Meister, que tratam da educação corporativa e sua relação com a inovação nas organizações (PORTES, 2010).

Segundo Freire (2013, p. 54-56), a pesquisa teórica "[...] promove um diálogo subjetivo entre autores". A pesquisa exploratória "[...] tem o objetivo de promover a primeira aproximação com o tema para conhecer os fatos e fenômenos relacionados [...]", enquanto a pesquisa descritiva "[...] tem o objetivo de levantar as características conhecidas sobre os elementos de análise para descrever em detalhes os componentes do fenômeno."

Marconi e Lakatos (1999, p. 27) definem que a "[...] pesquisa bibliográfica é um apanhado geral sobre os principais trabalhos já realizados, revestidos de importância por serem capazes de fornecer dados atuais e relevantes relacionados ao tema". Esse foi o meio utilizado neste este estudo e que the deu consistência interna.

\section{EDUCAÇÃO CORPORATIVA COMO FERRAMENTA PARA A INOVAÇÃO}

Ao analisar os dados coletados no levantamento bibliográfico, percebe-se que de formas diferentes os diversos autores relacionam direta ou indiretamente o desempenho dos trabalhadores com a inovação nas organizações que buscam desenvolver vantagens competitivas sustentáveis. A gestão do conhecimento aparece como fator-chave que permeia o ambiente dessas organizações e a educação corporativa como ferramenta para desenvolver as capacidades dos trabalhadores. No quadro 8 apresentamos essas relações. 
Quadro 8 - Relação da Educação Corporativa como ferramenta para a Inovação nas organizações que buscam desenvolver vantagens competitivas sustentáveis

\begin{tabular}{|c|c|}
\hline Autor & Relações Identificadas \\
\hline $\begin{array}{l}\text { Davenport e Prusak } \\
\text { (1998) }\end{array}$ & $\begin{array}{l}\text { As dinâmicas do mundo competitivo globalizado são forças motrizes para as empresas se } \\
\text { reinventarem e perceberem que a gestão dos ativos intangíveis é crucial para buscar uma } \\
\text { vantagem sustentável e se diferenciar no mercado. } \\
\text { A verdadeira vantagem competitiva está na capacidade e na velocidade do aprendizado } \\
\text { das pessoas nas organizações. }\end{array}$ \\
\hline $\begin{array}{l}\text { Teixeira Filho } \\
(2000)\end{array}$ & $\begin{array}{l}\text { A dimensão do trabalho mudou, do trabalho manual para o intelectual, e, por consequência, } \\
\text { o perfil dos trabalhadores também mudou, exigindo colaboradores com novas } \\
\text { competências e motivados ao aprendizado contínuo. } \\
\text { "A empresa começa a perceber a importância de transformar seu conhecimento } \\
\text { realmente em um ativo a serviço da organização, e não apenas em propriedade de } \\
\text { indivíduos ou grupos internos." (p. 41). } \\
\text { "A inovação permanente é um fator crítico de sucesso das organizações." (p. 42). }\end{array}$ \\
\hline $\begin{array}{l}\text { Iata e Zimmer } \\
(2016)\end{array}$ & $\begin{array}{l}\text { É preciso o desenvolvimento não somente da organização, mas também de competências } \\
\text { dos trabalhadores voltadas para a inovação. } \\
\text { Um processo de gestão da inovação promove e cria um ambiente para a inovação, para } \\
\text { a geração de ideias e projetos inovadores de forma contínua e permanente. }\end{array}$ \\
\hline Senge (2012) & $\begin{array}{l}\text { Aprendizagem contínua precisa estar contida na cultura organizacional. É determinante } \\
\text { para o sucesso organizacional que a empresa precisa continuamente desenvolver seus } \\
\text { trabalhadores, os frutos desse investimento será uma força de trabalho capaz de } \\
\text { aprender a aplicar seus novos conhecimentos no dia a dia, gerando contínuas melhorias } \\
\text { e inovações e, por consequência, a desejada vantagem competitiva sustentável. }\end{array}$ \\
\hline OCDE (2005) & $\begin{array}{l}\text { O conhecimento é criado e compartilhado dentro da empresa e entre empresas e com outras } \\
\text { organizações. Isso gera a necessidade latente de ter trabalhadores qualificados que } \\
\text { possam contribuir de forma sólida na interação com outras empresas e instituições públicas } \\
\text { de pesquisa que fazem parte do ecossistema de inovação, conduzindo à exploração do } \\
\text { conhecimento. }\end{array}$ \\
\hline $\begin{array}{l}\text { Nonaka e Takeuchi } \\
\text { (1997) }\end{array}$ & $\begin{array}{l}\text { A criação do conhecimento organizacional é a chave para a inovação nos negócios. Essa } \\
\text { é a base das empresas japonesas, elas são peritas em fomentar a inovação de forma contínua, } \\
\text { incremental e em espiral. Esses são os ingredientes para a obtenção de vantagens } \\
\text { competitivas sustentáveis. } \\
\text { A gestão do conhecimento, implícito e explícito, é o combustível para a inovação nas } \\
\text { organizações, seja em seus processos de gestão ou em seus produtos (bens e serviços). A } \\
\text { essência da inovação é recriar com base em ideais e ideias, para isso é necessário um } \\
\text { compromisso pessoal dos funcionários com a missão da organização. }\end{array}$ \\
\hline Meister (1999) & $\begin{array}{l}\text { A Universidade Corporativa (UC) vai muito além do treinamento de funcionários para } \\
\text { desempenhar tarefas. } \\
\text { O modelo de aprendizagem em rede reforça que o diferencial competitivo está em não } \\
\text { somente capacitar seus funcionários, mas seus fornecedores e clientes também. }\end{array}$ \\
\hline Eboli (2004) & $\begin{array}{l}\text { A finalidade básica da EC em uma organização é fomentar "[...] o desenvolvimento e a } \\
\text { instalação das competências empresariais e humanas consideradas críticas para a } \\
\text { viabilização das estratégias de negócios." (p. 48). } \\
\text { Na Terceira Revolução Industrial, o ambiente de constantes mudanças tornou imperativo o } \\
\text { desenvolvimento das pessoas com autonomia, iniciativa e dinamismo, com foco na } \\
\text { aprendizagem contínua. }\end{array}$ \\
\hline Freire et al. (2016) & $\begin{array}{l}\text { A partir da década de } 1980 \text { e, principalmente na década de } 1990 \text {, com o cenário de } \\
\text { hipercompetitividade mundial houve a proliferação das Universidade Corporativas (UC), } \\
\text { alinhada à necessidade de capacitação e atualização contínua dos trabalhadores. } \\
\text { "A atuação em redes de aprendizagem torna-se o principal caminho para a inovação." } \\
\text { (p. 3). }\end{array}$ \\
\hline
\end{tabular}

Fonte: Elaborado pelos autores (2016).

Constatou-se que o Modelo de Inovação Hélice Tríplice e que o Modelo de Educação Corporativa UCR são considerados mais contemporâneos em suas áreas e apresentam uma característica em comum, o trabalho em rede. 
Característica fundamental que as organizações da sociedade da informação buscam para desenvolver vantagens competitivas sustentáveis.

Identificou-se que o Modelo de Educação Corporativa, Universidade Corporativa em Rede (UCR), proposto por Freire et al. (2016), é o modelo de educação corporativa mais adequado para ser incorporado pelas empresas que visam ao desenvolvimento de vantagens competitivas a partir da inovação em processos e produtos (bens e serviços), com o objetivo de potencializar os esforços individuais e organizacionais, desenvolvendo possíveis lacunas da educação acadêmica nos trabalhadores e stakeholders das organizações.

\section{CONSIDERAÇÕES FINAIS}

A análise bibliográfica realizada permitiu visualizar evidências teóricas que sustentam o objetivo deste estudo e respondem à situação-problema levantada nesta pesquisa.

Atendendo ao objetivo deste estudo, constatou-se que a educação corporativa pode ser uma importante ferramenta para o desenvolvimento de competências, habilidades e atitudes dos trabalhadores, de modo a estimular a cultura de aprendizado contínuo e promover a inovação em processos e produtos (bens e serviços), contribuindo para a construção de vantagens competitivas sustentáveis das organizações no mercado hipercompetitivo da sociedade da informação, pois trabalhadores mais qualificados podem contribuir de forma sistemática e contínua, inovar em processos e produtos, em prol da competitividade das organizações.

Respondendo à questão de pesquisa, identificou-se que o modelo de educação corporativa UCR, proposto por Freire et al. (2016), é mais contemporâneo e que melhor poderia contribuir para o desenvolvimento dos trabalhadores, sendo o mais adequado para ser incorporado pelas empresas que visam o desenvolvimento de vantagens competitivas a partir da inovação em processos e produtos (bens e serviços), visando potencializar os esforços individuais e organizacionais, pois em seus princípios valoriza o desenvolvimento em rede, essencial para atuação no mercado globalizado.

Percebe-se que a gestão do conhecimento tem papel singular no desempenho organizacional e possibilita respostas mais rápidas e ciclos de melho- 
rias contínuas estruturadas que, quando associadas à qualificação dos trabalhadores, possibilitam um desempenho superior das organizações.

Um estudo realizado por Fonseca e Cunha (2015) para a Confederação Nacional da Indústria (CNI) corrobora as constatações desta pesquisa, apresentando que:

O aumento continuado da competitividade depende do aumento da produtividade, ou seja, de mudanças estruturais, na capacidade de produzir do país. Em suma, o futuro da indústria brasileira depende da retomada do crescimento da produtividade, o que requer educação, isto é, trabalho qualificado, e investimento, sobretudo, em inovação. (FONSECA; CUNHA, 2015. p. 15).

Notou-se que a educação corporativa tem sido uma prática muito valorizada nos últimos anos pelas organizações, porém, de acordo com Eboli, Hourneaux Junior e Cassimiro (2011), esse assunto carece de mais pesquisa no Brasil. Nos Estados Unidos, onde a Educação Corporativa foi consolidada na década de 1980, existem muitos estudos sobre a aplicação do tema nas organizações. Portanto, ter mais pesquisas na área é essencial para conhecer a realidade brasileira.

Por fim, como sugestão para pesquisas futuras, sugere-se a realização de estudos que analisem a situação atual dos sistemas de educação corporativa nas organizações brasileiras, a fim de identificar possíveis lacunas e verificar se há contribuições que possam ser feitas à luz da revisão teórica apresentada neste capítulo, bem como identificar se as práticas das organizações validam (ou não) as constatações teóricas desta pesquisa.

\section{REFERÊNCIAS BIBLIOGRÁFICAS}

ABEL, A. L.; LI, J. Exploring the Corporate University Phenomenon: development and implementation of a comprehensive survey. Human Resource Development Quartely, v. 23, n. 1, spring 2012.

ALLEN, M. (Ed.). The Corporate University Handbook: Designing, Managing and Growing a Successful Program. New York: Amacom, 2002. 256 p. 
ANDERSON, M. H.; SUN, P. Y. T. What have scholars retrieved from Walsh and Ungson (1991)? A citation context study. Management Learning, v. 41, n. 2, p. 131-145, 2010.

ANTONELLI, G. A. C.; CAPPIELlO G. B. C.; PEDRINI G. A. C. The Corporate University in the European utility industries. Utilities Policy, v. 25, p. 33-41, 2013. BUCHBINDER, $\mathrm{H}$. The market oriented university and the changing role of knowledge. Higher Education: International Journal of Higher Education and Educational Planning, v. 26, p. 331-347, 1993.

BUCHBINDER, H.; JANICE, N. The Service University and Market Forces. Academe, v. 78, n. 4, p. 13-15, jul./ago. 1992.

CIANCONI, R. Gestão da informação na sociedade do conhecimento. Brasília: SENAI/DN, 2001.

CLARK, B. R. Creating Entrepreneurial Universities: Organizational Pathways of Transformation. Issues in Higher. New York: Elsevier, 1998.

CONDE, M. V. F.; ARAÚJO-JORGE, T. C. Modelos e concepções de inovação: a transição de paradigmas, a reforma da C\&T brasileira e as concepções de gestores de uma instituição pública de pesquisa em saúde. Ciência \& Saúde Coletiva, v. 8, n. 3, p. 727-741, 2003. Disponível em: <http://www.scielo.br/pdf/ csc/v8n3/17453>. Acesso em: 27 maio 2016.

DAVENPORT, T. H.; PRUSAK, L. Conhecimento empresarial: como as organizações gerenciam o seu capital intelectual. 3. ed. Rio de Janeiro: Campus, 1998. 237 p.

EBC AGÊNCIA BRASIL. Quarta revolução industrial é tema do Fórum Econômico Mundial em Davos. Publicado em 20 jan. 2016. Disponível em: <http:// agenciabrasil.ebc.com.br/internacional/noticia/2016-01/quarta-revolucaoindustrial-e-tema-do-forum-economico-mundial-em-davos>. Acesso em: 05 jun. 2016.

EBOLI, M. Educação corporativa no Brasil: mitos e verdades. São Paulo: Editora Gente, 2004.

EBOLI, M. P.; HOURNEAUX JUNIOR, F.; CASSIMIRO, W. T. Educação corporativa: governança, dinâmica e estrutura das universidades corporativas no Brasil. Rio de Janeiro: ANPAD, 2011.

FONSECA, R. da; CUNHA, S. Indústria brasileira: da perda de competitividade à recuperação? Brasília: Confederação 
Nacional da Indústria, 2015. Disponível em: <http://arquivos. portaldaindustria.com.br/app/cni_estatistica_2/2016/02/03/205/ IndicadoresDeCompetitividadeDalndustriaBrasileira_2015.pdf>. Acesso em: 05 jun. 2016.

FORBES BRASIL. O que é a quarta revolução industrial. Publicado em $27 \mathrm{fev}$. 2016. Disponível em: <http://www.forbes.com.br/fotos/2016/02/o-que-e-aquarta-revolucao-industrial/\#foto4>. Acesso em: 05 jun. 2016.

FREIRE, P. de S. Aumente a qualidade e quantidade de suas publicações científicas: manual para elaboração de projetos e artigos científicos. Curitiba: CRV, 2013.

FREIRE, P. de S. et al. Universidade Corporativa em Rede: Considerações Iniciais para um Novo Modelo de Educação Corporativa. Revista Spacios, v. 37, n. 5, 2016. Disponível em: <http://www.revistaespacios.com/a16v37n05/163705e5. html>. Acesso em: 27 abr. 2016.

FUNDAÇÃO NACIONAL DA QUALIDADE - FNQ. Modelo de Excelência da Gestão. São Paulo: FNQ, 2016. Disponível em: <http://www.fnq.org.br/avalie-se/ metodologia-meg/modelo-de-excelencia-da-gestao>. Acesso em: 05 jun. 2016.

GANZER, P. P. et al. Modelo de processo tecnológico: uma evolução histórica de modelo linear para modelo interativo. Gestão Contemporânea, Porto Alegre, v. 16, jul./dez. 2014. Disponível em: <http://seer4.fapa.com.br/index.php/ arquivo/article/view/428>. Acesso em: 27 maio 2016.

GOMES, M. A. S.; PEREIRA, F. E. C. Hélice Tríplice: um ensaio teórico sobre a relação universidade-empresa-governo em busca da inovação. International Journal Knowledge Engineering and Management, Florianópolis, v. 4, n. 8, p. 136-155, mar./jun. 2015. Disponível em: <http://incubadora.periodicos.ufsc.br/ index.php/IJKEM/article/view/3309>. Acesso em: 27 maio 2016.

IATA, C. M.; ZIMMER, P. (Orgs.) Inovação em rede: como inserir sua empresa no ecossistema de inovação. Florianópolis: Tribo da Ilha, 2016. 314 p.

JONGBLOED, B. W. A.; GOEDEGEBUURE, L. C. G. From the entrepreneurial University to the Stakeholder University. In: Proceedings of The Internacional Congress on Universities and Regional Development in Knowledge Society. Barcelona: Universitat Politécnica de Catalunya, 2001, p. 232-251.

KLEIN, D. A. A gestão estratégica do capital intelectual: recursos para a economia baseada em conhecimento. Rio de Janeiro: Qualitymark, 1998. 
MARCONI, M. de A.; LAKATOS, E. M. Técnicas de Pesquisa. São Paulo: Atlas, 1999. MARGHERITA, A.; SECUNDO, G. The Emergence of the Stakeholder University. In: ROMANO, A. (Ed.). Open Business Innovation Leadership: The Emergence of the Stakeholder University. Londres: Palgrave Macmillan, 2009, p. 170-207.

MARGINSON, S.; CONSIDINE, M. The Enterprise University: power, governance and reinvention in Australia. Melbourne: Cambridge University Press, 2001.

MCGEE, P. Corporate Universities: Competitors or Collaborators? The Journal of Human Resource and Adult Learning, USA, v. 2, n. 1, p. 28-32, maio 2006.

MEISTER, J. Corporate Universities: Lessons in building a worldclass work force. New York: McGrawHill, 1998.

MEISTER, J. Educação Corporativa. São Paulo: Makron Books, 1999.

MORRISON, J. L.; MEISTER, J. C. Corporate Universities: An Interview with Jeanne Meister. The Technology Source Archives at the University of North Carolina, jul./ago. 2000. Disponível em: <http://technologysource.org/article/corporate_ universities/>. Acesso em: 08 jan. 2016.

NONAKA, I.; TAKEUCHI, H. Criação de conhecimento na empresa. Rio de Janeiro: Campus, 1997.

ORGANIZAÇÃO PARA A COOPERAÇÃO E DESENVOLVIMENTO ECONÔMICO - OCDE. Manual de Oslo: Proposta de diretrizes para coleta e interpretação de dados sobre inovação. 3. ed. Paris: OCDE, 2005. Disponível em: <http:// download.finep.gov.br/imprensa/oslo2.pdf>. Acesso em: 28 maio 2016.

PORTES, M. da C. de O. Educação corporativa como política pública: a ação do Ministério do Desenvolvimento, Indústria e Comércio Exterior. 2010. 109 f. Dissertação (Mestrado Profissional em Educação Profissional em Saúde) - Escola Politécnica de Saúde Joaquim Venâncio, Rio de Janeiro, 2010.

RADEMAKERS, M. Corporate Universities: driving force of knowledge innovation. Journal of Workplace Learning, v. 17, p. 130-136, 2005.

REIS, G. G.; SILVA, L. M. T. da; EBOLI, M. P. A prática reflexiva e suas contribuições para a educação corporativa. REGE, São Paulo, v. 17, n. 4, p. 403-419, out./dez. 2010. Disponível em: <http://www.revistas.usp.br/rege/article/view/36716>. Acesso em: 06 mar. 2016.

ROSSETI, A. G.; MORALES, A. B. O papel da tecnologia da informação na gestão do conhecimento. Ciência da Informação, v. 36, n. 1, p. 124-135, jan./abr. 2007. 
Disponível em: <http://www.scielo.br/pdf/ci/v36n1/a09v36n1.pdf>. Acesso em: 06 mar. 2016.

SENGE, P. M. A quinta disciplina: arte e prática da organização que aprende. 28. ed. São Paulo: Best Seller, 2012. 530 p.

SILVA, S. L. Da. Gestão do conhecimento: uma revisão crítica orientada pela abordagem da criação do conhecimento. Ciência da Informação, Brasília, v. 33, n. 2, p. 143-151, maio/ago. 2004. Disponível em: <http://www.scielo.br/pdf/ci/ v33n2/a15v33n2>. Acesso em: 06 mar. 2016.

SOUZA, P. R. A revolução gerenciada: educação no Brasil 1995-2002. São Paulo: Prentice-Hall, 2005.

TAURION, C. A Quarta Revolução Industrial chegou, e você não passará imune a ela. Computerworld. Publicado em 26 jan. 2016. Disponível em: <http:// computerworld.com.br/quarta-revolucao-industrial-chegou-e-voce-naopassara-imune-ela>. Acesso em: 05 jun. 2016.

TEIXEIRA FILHO, J. Gerenciando Conhecimento: como a empresa pode usar a memória organizacional e a inteligência competitiva no desenvolvimento de negócios. Rio de Janeiro: SENAC, 2000.

TIERNEY, W. G. (Org.). The Responsive University: Restructuring for High Performance. Baltimore: Johns Wopkins University Press, 1998. 181 p.

VALENTE, L. Hélice tríplice: metáfora dos anos 90 descreve bem o mais sustentável modelo de sistema de inovação. Conhecimento \& Inovação, Campinas, v. 6, n. 1, 2010. 